\title{
An echocardiographic assessment of atrial mechanical behaviour
}

\author{
Christopher J H Jones, Guo Jie Song, Derek G Gibson
}

\begin{abstract}
Relations between movement of the atrioventricular ring and changes in left atrial and ventricular dimensions were studied by echocardiography and compared with apexcardiography and Doppler mitral flow velocity traces in 20 healthy controls and in patients with left ventricular hypertrophy $(n=28)$ or dilatation ( $n=16)$. During left ventricular systole the atrioventricular ring, a structure common to ventricle and atrium, moved towards the ventricular apex, thus increasing left atrial volume. This action matched pulmonary venous return because it was in phase with the transverse left atrial dimension measured from aortic root to posterior left atrial wall. During early diastole, the mitral ring moved rapidly towards the atrium as transmitral flow accelerated. This requires a force directed from ventricle to atrium, likely to be the result of elastic recoil arising from compression of the ventricular myocardium or stretching of the atrial myocardium during ventricular systole. Two additional mechanisms of ventricular filling with atrial systole were recognised: (a) an increase in ventricular volume as the atrioventricular ring moved upwards and (b) transverse left ventricular expansion by pressure driven transmitral flow. The former is undetectable by Doppler from the apex; it accounted for $10 \%$ of ventricular filling in the healthy controls, but for significantly less in those with ventricular dilatation. In left ventricular hypertrophy, left ventricular filling was maintained by both mechanisms compensating for the reduced increase in volume early in diastole.

Interactions between the atrium and ventricle are functionally important during ventricular systole, early diastole, and in atrial systole. They are not included in the traditional separation of atrial function into reservoir, conduit, and pump functions.
\end{abstract}

In many patients with ventricular disease standard clinical investigations showed increased atrial contractile activity. ${ }^{1-3}$ This almost certainly represents a mechanism by which ventricular function is optimised, ${ }^{4}$ and presumablv it develops because of information transf "red from a diseased ventricle to the corresponding atrium. The mechanism of such an interaction remains unknown. Standard descriptions of atrial function do not invoke any influence of either systolic or diastolic ventricular function, ${ }^{5-7}$ neither do they explain why increased atrial activity in apparently similar patients may give rise to different changes in atrial pressures or flow rates. We have attempted to understand these processes by the study of atrial and ventricular wall motion during diastole and its relation to atrial pressure and flow rate, which we assessed by simple non-invasive techniques in healthy controls and patients with ventricular disease.

\section{Patients and methods}

PATIENTS

M mode echocardiograms, Doppler echocardiographic mitral velocity traces, and apexcardiograms were obtained in 28 patients with left ventricular hypertrophy and 16 with dilated cardiomyopathy and sinus rhythm. We also studied 20 healthy controls (aged 53 (12) years) with normal amplitude and timing of ventricular wall motion on minor axis echocardiography.

Patients with left ventricular hypertrophy had end diastolic septal or posterior wall thickness $>12 \mathrm{~mm}$ (upper limit of normal) on $M$ mode echocardiography. ${ }^{8}$ Three of these patients had hypertrophic cardiomyopathy; of the remainder with secondary hypertrophy, seven had aortic stenosis, 15 arterial hypertension, two had undergone aortic valve replacement, and one repair of coarctation.

All patients with dilated cardiomyopathy had increased left ventricular end diastolic $(>5.5 \mathrm{~cm})$ and end systolic dimensions $(>4 \mathrm{~cm})$ and fractional shortening below $23 \%$, the lower limit of the $95 \%$ confidence interval in our healthy controls. In nine patients the diagnosis was coronary artery disease; the remainder had idiopathic cardiomyopathy. Seven had mild functional mitral regurgitation detected by Doppler echocardiography.

\section{METHODS}

We obtained $M$ mode and cross sectional echocardiograms with the patient lying in the left lateral position. We used an Advanced Technical Laboratory $860 \mathrm{C}$ imager equipped with a $3.5 \mathrm{MHz}$ mechanical transducer. $M$ mode echocardiograms, Doppler mitral velocity traces, and apexcardiograms were recorded separately on a Honeywell (Ecoline 22) strip chart recorder at a paper speed of 
Figure 1 Drawing of apical four chamber cross sectional view showing the $M$ mode cursor positioned through the anterior tricuspid ring and the posterior mitral ring. Movements of the atrioventricular ring reflect changes in long axis dimensions of atria and ventricles.

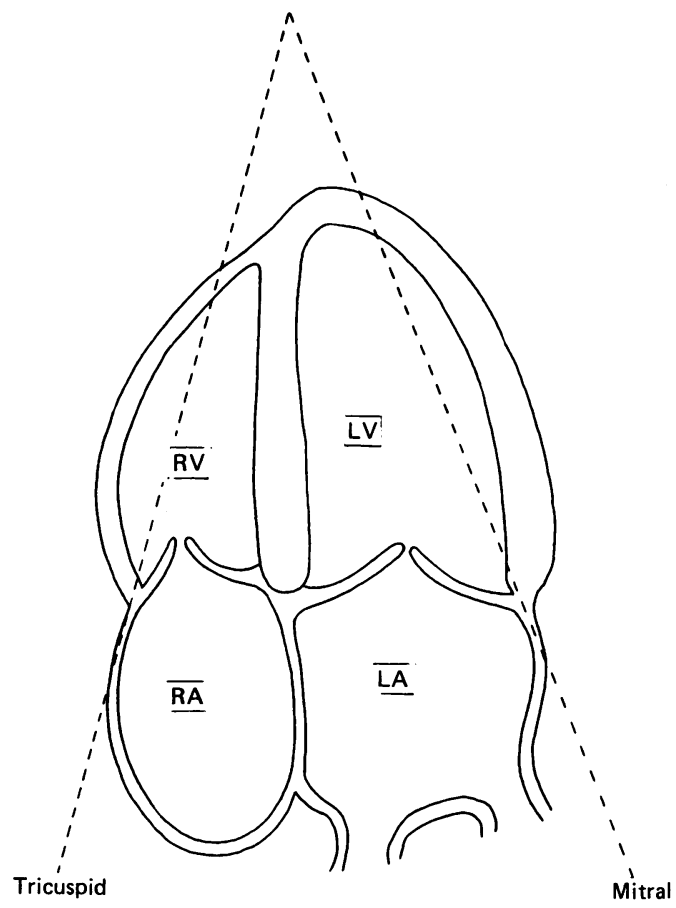

$100 \mathrm{~mm} / \mathrm{s}$ with simultaneous electrocardiogram and phonocardiogram.

Standard $M$ mode echocardiograms of the left ventricular minor axis were recorded at the level of the mitral leaflet. Because movements of the base of the heart reflect changes in atrial and ventricular volumes we also obtained $M$ mode echocardiograms of the atrioventricular ring after longitudinal placement of a cursor through the anterior tricuspid and posterior mitral valve rings, visualised on the apical four chamber view (fig 1). We compared mitral ring movement with changes in the anteroposterior

Figure 2 Two components of diastolic left ventricular filling superimposed from matched beats in the same patient. $(A)$ Doppler mitral flow velocity trace and $(B)$ motion of mitral ring towards the left atrium representing expansion of the lef ventricular long axis. The effective mitral valve area is deemed to be the same for each mechanism.
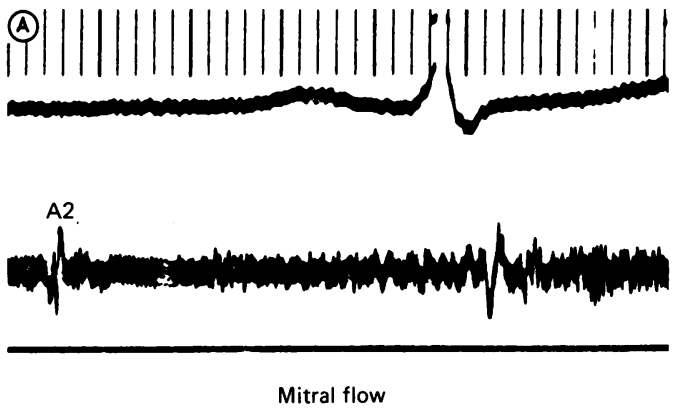

(B)
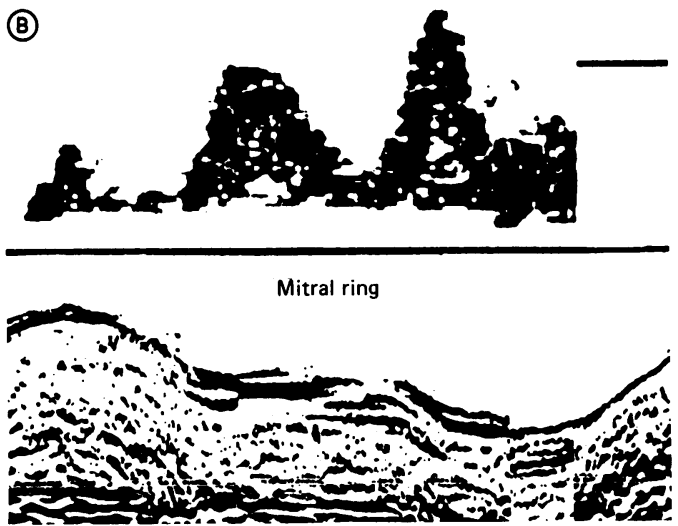

left atrial dimension assessed from cross sectionally guided $M$ mode echocardiograms at aortic valve level. A good quality Doppler signal representing mitral diastolic velocity was obtained from the cardiac apex by a Doptek system with $2 \mathrm{MHz}$ transducer and was recorded with frequency shift calibration. The apexcardiogram was separately recorded.

All recordings were matched for heart rate. The echocardiograms were digitised and the following measurements were taken:

Atrioventricular ring and posterior aortic root

(a) Extent and direction of movement during ventricular systole $(\mathrm{cm})$.

(b) Extent, direction, and peak velocity of movement in early diastole $(\mathrm{cm}, \mathrm{cm} / \mathrm{s})$.

(c) Extent and direction of movement during atrial systole $(\mathrm{cm})$; the extent is also expressed as a proportion of the total excursion (\%).

(d) Transverse left atrial dimensions at end diastole ( $Q$ wave) and end systole (mitral valve opening) (cm).

\section{Transmitral flow velocity}

(a) Peak velocity during early diastole $(\mathrm{m} / \mathrm{s})$.

(b) Peak velocity during atrial systole $(\mathrm{m} / \mathrm{s})$.

(c) Time integrals, defined as the areas beneath the velocity curves, during early diastole and atrial systole $(\mathrm{cm})$.

\section{Apexcardiogram}

(a) 'a' wave amplitude, expressed as a proportion of the total amplitude (\%).

\section{Left ventricular minor axis echocardiogram}

(a) Isovolumic relaxation time defined as the interval from aortic valve closure to mitral valve opening.

(b) Peak rate of dimension change in diastole $(\mathrm{cm} / \mathrm{s})$ as a proportion of the total increase $(\%)$. (c) Dimension change during atrial systole expressed as a proportion of the total increase $(\%)$.

(d) Septal and posterior wall thickness $(\mathrm{cm})$

(e) Peak rate of posterior thinning $(\mathrm{cm} / \mathrm{s})$.

(f) Fractional shortening.

During diastole the greater part of the blood volume expanding the left ventricle may be calculated as the product of the time integral of the mitral velocity trace, dimensionally equivalent to a distance, and the effective mitral valve area. A smaller volume of blood enters the ventricle because the mitral ring is carried back over it as the long axis expands (fig 2). This volume is the product of the mitral ring displacement during filling and the mitral valve area because the effective valve area is the same for both components of the volume increase. The component due to mitral ring movement does not involve movement of blood and so is unlikely to be detected by Doppler echocardiography. The ratio of mitral ring displacement to the time integral of mitral velocity alone represents the ratio of long axis ventricular filling to the remainder, and was calculated in all patients during early and late diastole.

All results were expressed as the mean (1 SD). The significance of the differences between means in the different groups was tested by unpaired $t$ tests. 
Table 1 Atrioventricular ring movement (mean (1SD))

\begin{tabular}{|c|c|c|c|}
\hline & Controls & $\begin{array}{l}\text { Left ventricular } \\
\text { hypertrophy }\end{array}$ & $\begin{array}{l}\text { Left ventricular } \\
\text { dilatation }\end{array}$ \\
\hline $\begin{array}{l}\text { Ventricular systole: } \\
\text { Onset mitral (ms) } \\
\text { Onset tricuspid (ms) } \\
\text { Excursion mitral (cm) } \\
\text { Excursion tricuspid (cm) }\end{array}$ & $\begin{array}{l}80(40) \\
50(20) \\
1 \cdot 4(0 \cdot 3) \\
2 \cdot 6(0 \cdot 5)\end{array}$ & $\begin{array}{l}110(35) \\
70(40) \\
1 \cdot 2(0 \cdot 3) \\
2 \cdot 3(0 \cdot 4)\end{array}$ & $\begin{array}{l}125(85) \\
55(50) \\
0.7(0.2) \dagger \\
1.6(0.6) \dagger\end{array}$ \\
\hline $\begin{array}{l}\text { Early diastole: } \\
\text { Velocity mitral }(\mathrm{cm} / \mathrm{s}) \\
\text { Velocity tricuspid }(\mathrm{cm} / \mathrm{s}) \\
\text { Excursion mitral }(\mathrm{cm}) \\
\text { Excursion tricuspid }(\mathrm{cm})\end{array}$ & $\begin{array}{l}7 \cdot 0(3 \cdot 0) \\
8 \cdot 0(3.0) \\
0.7(0 \cdot 2) \\
1 \cdot 1(0 \cdot 4)\end{array}$ & $\begin{array}{l}5 \cdot 0(1 \cdot 7) \dagger \\
8 \cdot 5(2 \cdot 4) \\
0 \cdot 5(0 \cdot 3)^{\star} \\
1 \cdot 1(0 \cdot 3)\end{array}$ & $\begin{array}{r}5 \cdot 0(2 \cdot 0)^{\star} \\
11 \cdot 0(4 \cdot 0) \dagger \\
0 \cdot 4(0 \cdot 2) \dagger \\
0 \cdot 9(0 \cdot 6)\end{array}$ \\
\hline $\begin{array}{l}\text { Atrial systole: } \\
\text { Excursion mitral }(\mathrm{cm})(\%) \\
\text { Excursion tricuspid }(\mathrm{cm})(\%)\end{array}$ & $\begin{array}{l}0.6(0.2)(40(16)) \\
1.0(0.4)(43(14))\end{array}$ & $\begin{array}{l}0.7(0 \cdot 2)\left(50(12)^{\star}\right) \\
1 \cdot 1(0 \cdot 4)(46(14))\end{array}$ & $\begin{array}{l}0.3(0.2) \dagger(28(15) \dagger) \\
0.4(0.40) \dagger(37(24))\end{array}$ \\
\hline
\end{tabular}

${ }^{\star} p<0.05$ and $\dagger p<0.01$ compared with controls.

\section{Results}

CONTROLS

Movement of the atrioventricular ring (table 1).- The atrioventricular ring moved down towards the ventricles throughout ventricular systole and up towards the atria during early diastole and atrial systole, with a pause during mid-diastole. The tricuspid ring moved further than the mitral ring during both ventricular and atrial systole (ventricular systole $2.6(0.5) v$ $1.4(0.3) \mathrm{cm}, \mathrm{p}<0.01$; atrial systole $1(0.4) v$ $0.6(0.2) \mathrm{cm}, \mathrm{p}<0.01)$. But as a proportion of the total movement, atrial systole caused similar upward displacement of the right and left sides. Mitral ring excursion was responsible for $8(2 \cdot 1) \%$ of the total increase in left ventricular volume during early diastole and 10 (3.9)\% of the total during atrial systole.

Anteroposterior left atrial dimension (table 2).The anteroposterior dimension increased during ventricular systole reaching a peak with mitral valve opening, and fell during diastole. These changes were less than those of the mitral ring during ventricular systole $(1(0.2) v$ $1.4(0.3) \mathrm{cm}, \mathrm{p}<0.01)$ and early diastole $(0.5$ $(0.1) v 0.7(0.2) \mathrm{cm}, \mathrm{p}<0.05)$. During atrial systole anteroposterior change and mitral ring excursion were similar (both $0.6(0.2) \mathrm{cm}$ ). Movements were effectively synchronous throughout the cardiac cycle, with that of the mitral ring preceding the anteroposterior axis by $5(10) \mathrm{ms}$ at its onset, $25(50) \mathrm{ms}$ at its peak, and $10(50) \mathrm{ms}$ at the onset of atrial systole (all NS).

Table 2 Anteroposterior left atrial dimension (mean (1 SD))

\begin{tabular}{|c|c|c|c|}
\hline & Controls & $\begin{array}{l}\text { Left ventricular } \\
\text { hypertrophy }\end{array}$ & $\begin{array}{l}\text { Left ventricular } \\
\text { dilatation }\end{array}$ \\
\hline $\begin{array}{l}\text { Ventricular systole: } \\
\text { Onset (ms) } \\
\text { Excursion }(\mathrm{cm})\end{array}$ & $\begin{array}{l}80(25) \\
1.0(0 \cdot 2)\end{array}$ & $\begin{array}{l}100(40) \\
0.8(0 \cdot 2)^{\star}\end{array}$ & $\begin{array}{l}140(65) \dagger \\
0.4(0.2) \dagger\end{array}$ \\
\hline $\begin{array}{l}\text { Early diastole: } \\
\text { Velocity }(\mathrm{cm} / \mathrm{s}) \\
\text { Excursion }(\mathrm{cm})\end{array}$ & $\begin{array}{l}4(1) \\
0 \cdot 5(0 \cdot 1)\end{array}$ & $\begin{array}{l}3.5(1 \cdot 7) \\
0.3(0 \cdot 1) \dagger\end{array}$ & $\begin{array}{l}2.4(1 \cdot 0) \dagger \\
0.3(0 \cdot 2) \dagger\end{array}$ \\
\hline $\begin{array}{l}\text { Atrial systole: } \\
\text { Excursion }(\mathrm{cm})(\%)\end{array}$ & $0.6(0.2)(59(13))$ & $0.5(0.2)(63(21))$ & $0.3(0.2) \dagger(44(36) \dagger)$ \\
\hline $\begin{array}{l}\text { Anteroposterior dimension: } \\
\text { End ventricular systole }(\mathrm{cm}) \\
\text { End ventricular diastole }(\mathrm{cm})\end{array}$ & $\begin{array}{l}3 \cdot 0(0 \cdot 5) \\
2 \cdot 2(0 \cdot 5)\end{array}$ & $\begin{array}{l}3.4(0.6) \\
2.9(0.6)^{\star}\end{array}$ & $\begin{array}{l}3.7(1 \cdot 0) \\
3.3(0 \cdot 6)^{\star}\end{array}$ \\
\hline
\end{tabular}

${ }^{\star} \mathrm{p}<0.05$ and tp $<0.01$ compared with controls.
Standard assessment of atrial systole (table 3).The mitral flow velocity and the increase in the minor axis of the ventricle during atrial systole were $0.5(0.1) \mathrm{m} / \mathrm{s}$ and $31(17) \%$ respectively. The relative amplitude of the apexcardiogram 'a' wave was $12(6) \%$.

Left ventricular function (table 4).-Fractional shortening of the minor axis was $0.28(0.04)$, septal thickness was $1 \cdot 2(0 \cdot 2) \mathrm{cm}$, and posterior wall thickness was $1 \cdot 1(0 \cdot 25) \mathrm{cm}$. In diastole the isovolumic relaxation time was $70(20) \mathrm{ms}$ and the peak rates of change in the minor axis dimension and posterior wall thinning were 8.4 $(2 \cdot 8) \mathrm{cm} / \mathrm{s}$ and $6 \cdot 2(1 \cdot 6) \mathrm{cm} / \mathrm{s}$ respectively.

\section{LEFT VENTRICULAR HYPERTROPHY}

Atrioventricular ring movement.-The pattern of left atrioventricular ring motion was abnormal in patients with left ventricular hypertrophy. The extent and velocity of upward motion during early diastole were lower than normal (extent $0.5(0.3) \mathrm{cm}$, velocity $7(3) \mathrm{cm} / \mathrm{s}$; both $\mathrm{p}<0.01 v$ controls) and the distance moved during atrial systole was proportionately greater than normal $(50 \quad(12) \%$, $\mathrm{p}<0.05)$. Despite these changes the timing, pattern, and extent of right sided ring motion remained normal. The proportions of ventricular inflow due to mitral ring movement as distinct from transmitral flow during early diastole and atrial systole were similar to normal (8 (2)\% and 8 (4)\% respectively) (table 5).

Anteroposterior left atrial dimension.-A reduced anteroposterior change during ventricular systole $(0.8(0.2) \mathrm{cm}, \mathrm{p}<0.05 v$ controls) meant that the anteroposterior dimension was increased at ventricular end diastole (2.9 $(0.6) \mathrm{cm}, \mathrm{p}<0.05 v$ controls). Despite this, and despite reduced early diastolic movement $(0.3(0.1) \mathrm{cm}, \mathrm{p}<0.05 v$ controls), atrial systolic motion remained normal. Anteroposterior changes were synchronous with mitral ring motion as they were in the controls. Standard assessment of atrial systole.-The ' $a$ ' wave amplitude on the apexcardiogram and atrial systolic mitral flow velocity were increased (apexcardiogram 19 (11)\%, p $<0.05$ $v$ normal; velocity $0.7(0.2) \mathrm{m} / \mathrm{s}, \mathrm{p}<0.01$ $v$ controls (table 3 )). The increase in the minor axis during atrial systole was normal (34 (17) \%). 
Table 3 Standard assessment of atrial systole (mean (1 SD))

\begin{tabular}{llll}
\hline & Controls & $\begin{array}{l}\text { Left ventricular } \\
\text { hypertrophy }\end{array}$ & $\begin{array}{l}\text { Left ventricular } \\
\text { dilatation }\end{array}$ \\
\hline Minor axis increase (\%) & $31(17)$ & $34(17)$ & $21(15)^{\star}$ \\
Apexcardiogram 'a' wave (\%) & $12(6)$ & $19(11)^{\star}$ & $31(17)^{\star}$ \\
Mitral velocity (m/s) & $0.5(0 \cdot 1)$ & $0.7(0 \cdot 2) \dagger$ & $0.6(0 \cdot 3)$ \\
\hline
\end{tabular}

${ }^{\star} \mathrm{p}<0.05$ and $\dagger \mathrm{p}<0.01$ compared with controls.

Left ventricular function.-Fractional shortening $(0.33(0.66))$ was normal (table 4$)$. Early diastole was, however, abnormal and was characterised by increased isovolumic relaxation time $(90(30) \mathrm{ms}, \mathrm{p}<0.05 v$ controls $)$ and a reduced peak rate of posterior wall thinning $(4.6(1.8) \mathrm{cm} / \mathrm{s}, \mathrm{p}<0.01 v$ controls $)$.

\section{DILATED CARDIOMYOPATHY}

Atrioventricular ring movement.-Downward movement of the mitral and tricuspid rings during ventricular systole were both diminished (mitral $0.7(0.2) \mathrm{cm}$, tricuspid $1.6(0.6)$ $\mathrm{cm}$; both $\mathrm{p}<0.01 v$ controls). The pattern of upward movement differed on the right and left sides. During early diastole upward mitral ring displacement was diminished (extent $0.4(0.2)$ $\mathrm{cm}, \mathrm{p}<0.01 v$ normal, velocity $5(2) \mathrm{cm} / \mathrm{s}$, $\mathrm{p}<0.05 v$ controls), whereas a normal extent of upward tricuspid motion was maintained due to a considerably increased velocity (11 (4) $\mathrm{cm} / \mathrm{s}, \mathrm{p}<0.01 v$ controls). Upward motion of both sides during atrial systole was reduced (mitral 0.3 $(0.2) \mathrm{cm}$, tricuspid 0.4 (0.4) $\mathrm{cm}$; both $\mathrm{p}<0.01 v$ controls). The proportion of upward movement of the mitral ring to transmitral flow was normal in early diastole (6 (3)\%) but was reduced during atrial systole (3 (2), $\mathrm{p}<0.01 v$ controls).

Anteroposterior left atrial dimension.Anteroposterior left atrial change during ventricular systole was reduced $(0 \cdot 4(0 \cdot 2) \mathrm{cm}$, $\mathrm{p}<0.01 v$ normal) and the end diastolic dimension was increased $(3.3(0.6) \mathrm{cm}, \mathrm{p}<$ $0.01 v$ controls). The pattern of change during diastole was normal. Anteroposterior changes were again synchronous with changes in mitral ring position throughout the cardiac cycle.

Standard assessment of atrial systole.-Though the amplitude of the ' $a$ ' wave on the apexcardiogram was considerably raised $(31$ (17)\%, $\mathrm{p}<0.01 v$ controls), the increase in the minor axis of the left ventricle during atrial systole was reduced (21 (15)\%, p < 0.05 $v$ controls) and peak mitral flow velocity was normal $(0.6$ $(0 \cdot 3) \mathrm{m} / \mathrm{s}, \mathrm{p}=\mathrm{NS}$ ).

Left ventricular function.-Fractional shortening $(0 \cdot 16(0 \cdot 05))$ and septal thickness $(1 \cdot 0(0 \cdot 3)$

Table 4 Left ventricular function (mean (1 SD))

\begin{tabular}{|c|c|c|c|}
\hline Variable & $\begin{array}{l}\text { Controls } \\
(n=20)\end{array}$ & $\begin{array}{l}\text { Left ventricular } \\
\text { hypertrophy } \\
(n=28)\end{array}$ & $\begin{array}{l}\text { Left ventricular } \\
\text { dilatation } \\
(n=16)\end{array}$ \\
\hline $\begin{array}{l}\text { Fractional shortening } \\
\text { Posterior wall thickness }(\mathrm{cm}) \\
\text { Septal thickness }(\mathrm{cm}) \\
\text { Isovolumic relaxation time }(\mathrm{ms}) \\
\text { Peak rate of dimension increase }(\mathrm{cm} / \mathrm{s}) \\
\text { Peak rate of posterior wall thinning }(\mathrm{cm} / \mathrm{s}) \\
\text { RR interval (ms) }\end{array}$ & $\begin{array}{l}0 \cdot 28(0 \cdot 04) \\
1 \cdot 1(0 \cdot 25) \\
1 \cdot 2(0 \cdot 2) \\
70(20) \\
8 \cdot 4(2 \cdot 8) \\
6 \cdot 2(1 \cdot 6) \\
850(70)\end{array}$ & $\begin{array}{l}0 \cdot 33(0 \cdot 06) \\
1 \cdot 7(0 \cdot 4) \dagger \\
2 \cdot 5(0 \cdot 7) \dagger \\
90(30)^{\star} \\
7 \cdot 6(2 \cdot 7) \\
4 \cdot 6(1 \cdot 8) \dagger \\
910(60)\end{array}$ & $\begin{array}{l}0 \cdot 16(0 \cdot 05) \dagger \\
1 \cdot 2(0 \cdot 2) \\
1 \cdot 0(0 \cdot 3)^{\star} \\
40(30) \dagger \\
6 \cdot 7(3 \cdot 0) \\
3 \cdot 6(1 \cdot 9) \dagger \\
780(90)\end{array}$ \\
\hline
\end{tabular}

${ }^{\star} \mathrm{p}<0.05$ and $\dagger \mathrm{p}<0.01$ compared with controls.
Table 5 Ratio of long axis change to transmitral distance (\%)

\begin{tabular}{llll}
\hline & Controls & $\begin{array}{l}\text { Left ventricular } \\
\text { hypertrophy }\end{array}$ & $\begin{array}{l}\text { Left ventricular } \\
\text { dilatation }\end{array}$ \\
\hline Early diastole & $8 \cdot 0(2 \cdot 1)$ & $8 \cdot 4(1 \cdot 9)$ & $5 \cdot 8(3 \cdot 0)$ \\
Atrial systole & $9 \cdot 8(3.9)$ & $8 \cdot 2(4 \cdot 5)$ & $3.0(0 \cdot 6)^{\star}$ \\
\hline
\end{tabular}

${ }^{\star} \mathrm{p}<0.01$ compared with controls.

$\mathrm{cm})$ were reduced $(\mathrm{p}<0.05$ and $\mathrm{p}<0.01 v$ controls respectively). The isovolumic relaxation time was short $(40$ (30) ms, p $<0.01 v$ controls), suggesting raised left atrial pressure, and the peak rate of wall thinning was low (3.6 $(1.9) \mathrm{cm} / \mathrm{s}, \mathrm{p}<0.01 v$ controls).

\section{Discussion}

Though normal atrial function is well recognised as contributing significantly to ventricular filling, the way it does so has been little studied. We therefore adapted simple non-invasive methods based on ultrasound to see how changes in atrial and ventricular dimensions are related to those in transmitral flow velocity in healthy individuals and patients with ventricular disease.

Changes in left atrial volume can be assessed from the motion of the atrioventricular ring ${ }^{-11}$ and also from the anteroposterior diameter, itself reflected mainly in aortic root motion because the posterior aortic wall is fixed to the mediastinum. ${ }^{12}$ These two measurements differ in that the atrioventricular ring is also in contact with ventricular myocardium while the left atrial diameter is not. The anteroposterior diameter thus reflects left atrial events alone, ${ }^{13}$ whereas motion of the atrioventricular ring allows atrioventricular interactions to be studied.

In healthy individuals left atrial volume increases during ventricular systole because the mitral valve is closed and venous return continues. Two mechanisms can be identified. Pulmonary venous return derives ultimately from right ventricular systolic function. In addition to this, downward motion of the atrioventricular ring towards the apex of the ventricle, while an integral part of the normal contraction and ejection mechanisms of the ventricle, ${ }^{1014}$ also increases atrial volume and potentially facilitates the inflow of blood from the pulmonary veins. ${ }^{8}$ Though this latter mechanism involves forces very much greater than those resulting from the venous return, we found no evidence that either of these very different mechanisms predominated in healthy individuals because there was no significant phase delay between downward motion of the mitral ring and the increase in the anteroposterior axis. In addition, the extent and peak velocities of changes in the two axes of the left atrium that we measured were similar. Thus the rate of inflow of blood into the left atrium exceeds the potential volume increase due to atrioventricular ring motion alone, so that changes in atrial dimensions caused by left ventricular contraction and pulmonary venous inflow seem to be matched in resting healthy individuals. During ventricular diastole 
changes in the anteroposterior diameter and mitral ring position were also closely matched in extent, velocity, and timing. When the heart rate is slow, as it was in our subjects, changes in atrial dimensions reflect the characteristic tripartite filling pattern of left ventricular inflow, with a rapid fall during early diastole and again during atrial systole after the intervening period of diastasis. During early diastole, the fall in anteroposterior axis is the simple effect of left ventricular filling. Upward motion of the mitral ring, however, occurs in the face of increasing blood flow velocity across the mitral valve. Such acceleration implies a positive pressure difference from atrium to ventricle, so that movement of the atrioventricular ring in the opposite direction must be the result of a greater force. This force was not due to myocardial contraction because it operated during the time when both atrium and ventricle were relaxed. Thus is was likely to have been an elastic force, dissipating energy stored in the atrial or the ventricular wall at the end of the previous ventricular systole. Dissipation of energy stored in the atrial wall would be of theoretical interest as a ventricular restoring force with an anatomical basis outside rather than within the ventricle, the left atrium acting as a modified reservoir of stored energy derived from the ventricular myocardium rather than the venous return.

During atrial systole the long and anteroposterior atrial axes shortened equally. We found no evidence of regional non-uniformity in the extent or timing of atrial systole, as are present with normal ventricular systole. ${ }^{15}$ The increase in ventricular volume during atrial systole was brought about by two discrete mechanisms. It is usually assumed that the increase in ventricular volume during filling can be assessed from the product of the time integral of the transmitral flow velocity, usually detected by a Doppler transducer on the chest wall, and the effective mitral valve area. ${ }^{16}$ Motion of the mitral ring may modify this simple assumption, however. Keith deduced from anatomical considerations that because the atrioventricular ring moves towards the left atrium, blood within the left atrium at the start of atrial systole is within the left ventricle at the end. ${ }^{17}$ Because the blood itself does not move, no flow velocities can be detected by a transducer working from a fixed external reference point. Furthermore, this mechanism does not require the development of an atrioventricular pressure difference for its operation; and, unlike a simple increase in atrial pressure, it is directional, with no tendency for retrograde flow up the pulmonary veins. Since the effective mitral valve area for this mechanism was the same as for transmitral flow, we could estimate that upward motion of the mitral ring contributed approximately $10 \%$ of left ventricular filling during both early diastole and atrial systole in our normal group.

Events on the right side were in general similar to those on the left. As has been previously shown by angiography, ${ }^{18}$ the right atrioventricular ring moves further than the left during ventricular systole, presumably reflecting the striking differences in right and left ventricular fibre architecture. Despite altered left sided motion in left ventricular hypertrophy, the right side continued to move normally. In the patients with dilated cardiomyopathy the increased rate of expansion of right ventricular long axis in early diastole, indicated in this study by an increased velocity of upward tricuspid ring motion, has been described as the mechanism underlying the generation of a right ventricular third sound in the presence of raised atrial pressure. ${ }^{1920}$

Left atrial systole was significantly modified in disease. In patients with left ventricular hypertrophy, the apexcardiogram 'a' wave amplitude, reflecting pressure generated by the loaded atria, ${ }^{21}$ and transmitral flow velocity were increased. Mitral ring motion and changes in atrial anteroposterior dimension remained synchronous as in the healthy controls. In early diastole, however, the amplitude of upward motion of the mitral ring was diminished; and it was correspondingly increased during atrial systole, when the anteroposterior axis reduced normally, suggesting that atrial systolic shortening of the long axis may have been preferentially accentuated. Thus the increase in the left ventricular long axis matched the increase in minor axis. This was not the case in patients with dilated cardiomyopathy. Though the total amplitude of atrioventricular ring motion was reduced, presumably because of impaired ventricular systolic shortening, the relative change with left atrial systole was further diminished as was the contribution of ring motion to overall atrial flow. At the same time the relative prominence of the ' $a$ ' wave on the apexcardiogram increased, showing that the ability of the atrium to develop pressure was unimpaired. This combination of an increased pressure ' $a$ ' wave and a reduced transmitral flow is compatible with low end diastolic ventricular compliance. ${ }^{22}$

As a result of these studies we can extend traditional views on atrial function, which have divided it into reservoir, conduit, and pump functions. ${ }^{5-7}$ Reservoir function requires that the atrioventricular valves are closed, so that as atrial volume increases, pressure is determined passively by the compliance of the atria. Conduit function occurs when the valves are open and implies that the flow rate entering is equal to that leaving, so the volume of blood within the atria remains constant. It dissociates flow from volume changes in the atria and so cannot be detected from measurements of the pressure and volume or dimension of the atrium alone. Pump function represents work done on the circulating blood by the contracting atria. These functions do not take into account any interaction between the atria and adjacent structures, though such interactions clearly exist. Downward motion of the atrioventricular ring during ventricular contraction enlarges the atrial cavity in a manner quite unrelated to reservoir function, and the work done on the atria by this means may contribute to forward pulmonary venous flow. Then, in early diastole, atrial emptying by upward motion of the 
atrioventricular ring seems to be the result of elastic forces with their likely origin in ventricular systole. Upward motion of the atrioventricular ring during atrial systole may have the advantage of promoting an increase in the ventricular long axis in preference to pulmonary venous backflow, a mechanism that is lost in patients with reduced left ventricular compliance. These results indicate that, contrary to previous descriptions, the atria cannot be considered in isolation from the adjoining ventricles. For interpretation of measurements of atrial pressure and transmitral flow, these interrelations should be appreciated; this may lead to an improved understanding of how atrial mechanical behaviour could be altered to the advantage of patients with ventricular disease.

$\mathrm{CJHJ}$ was supported by a British Heart Foundation Junior Research Fellowship.

1 Bonow RO, Frederick TM, Bacharach SL, et al. Atrial systole and left ventricular filling in hypertrophic
cardiomyopathy: effect of verapamil. $\mathrm{Am} J$ Cardiol cardiomyopathy:

2 Rahimtoola SH, Ehsani A, Sinno MZ, Loeb HS, Rosen $\mathrm{KM}$, Gunnar RM. Left atrial transport function in myocardial infarction: importance of its booster pump function. Am J Med 1975;59:686-94

3 Matsuda $\mathrm{Y}$, Toma $\mathrm{Y}$, Ogawa $\mathrm{H}$, et al. Importance of left atrial function in patients with myocardial infarction. Circulation 1983;3:566-71.

4 Braunwald E, Frahm CJ. Studies on Starling's law of the heart IV. Observations on the hemodynamic functions of the left atrium in man. Circulation 1961;24:633-42.

5 Mitchell JH, Gilmore JP, Sarnoff SJ. The transport function of the atrium. Factors influencing the relation between mean left atrial pressure and left ventricular enddiastolic pressure. Am J Cardiol 1962;9:231-47.

6 Payne RM, Stone HL, Engelken EJ. Atrial function during volume loading. J Appl Physiol 1971;31:326-31.
7 Hitch DC, Nolan SP. Descriptive analysis of instantaneous left atrial volume - with special reference to left atrial left atrial volume-with special refer
function. $J$ Surg Res 1981;30:110-20.

8 Gibson DG, Traill TA, Hall RJC, Brown DJ. Echocardiographic features of secondary left ventricular hypertrophy. Br Heart $J$ 1979;41:54-9.

9 Keren G, Sonnenblick EH, LeJemtel TH. Mitral annulus motion. Relation to pulmonary venous and transmitral flows in normal subjects and in patients with dilated cardiomyopathy. Circulation 1988;78:621-9.

10 Hamilton WF, Rompf JH. Movements of the base of the ventricle and the relative constancy of the cardiac volume. Am J Physiol 1932;102:559-65.

11 Tsakiris AG, Padiya R, Gordon DA, Lipton I. Left atria size and geometry in the intact dog. Am $J$ Physiol 1977;232:H167-72.

12 Strunk BL, Fitzgerald KW, Lipton M, Popp RL, Barry WH. The posterior aortic wall echocardiogram; its WH. The posterior aortic wall echocardiogram; its
relationship to left atrial volume change. Circulation relationship to

13 Akgün G, Layton C. Aortic root and left atrial wall motion. An echocardiographic study. Br Heart J 1977;39:1082-7.

14 Jones CJH, Raposo L, Gibson DG. Functional importance of the long axis dynamics of the human left ventricle. Br Heart J 1990;63:215-20.

15 Shapiro E, Marier DL, St John Sutton MG, Gibson DG. Regional non-uniformity of wall dynamics in normal lef ventricle. Br Heart J 1981;45:264-70.

16 Kuo LC, Quinones MA, Rokey R, Sartori M, Abinader EG Zoghbi WA. Quantification of atrial contraction to left ventricular filling by pulsed Doppler echocardiography Cardiol 1987;59:1174-8.

17 Keith A. An account of the structures concerned in the production of the venous pulse. Journal of Anatomy and production of the venous
Physiology 1907;42:1-25.

18 Redington AN, Gray HH, Hodson ME, Rigby ML, Oldershaw PJ. Characterisation of the normal right ventricular pressure-volume relation by biplane angiography and simultaneous micromanometer pressure measurements. Br Heart J 1988;59:23-30

19 Ishimitsu T, Smith D, Berko B, Craige E. Origin of the third heart sound: comparison of ventricular wall dynamics in hyperdynamic and hypodynamic types. J Am Coll Cardio 1985;5:268-72.

20 Ozawa Y, Smith D, Craige E. Origins of the third heart sound. II. Studies in human subjects. Circulation 1983 67:399-404.

21 Benchimol A, Dimond EG, Carson JC. The value of the apexcardiogram as a reference tracing in phonocardiography. Am Heart $J$ 1961;61:485-93.

$22 \mathrm{Ng} \mathrm{KSK}$, Gibson DG. Relation of filling pattern to diastolic function in severe left ventricular disease. $B r$ Heart $J$ 1990;63:209-14. 